\title{
NUTRIÇÃO E PRODUÇÃO DE MATÉRIA SECA DE MILHO SUBMETIDO A CALAGEM E ADUBAÇÃO SULFATADA ${ }^{1}$
}

\author{
Leonidas Carrijo Azevedo Melo 2 , Júnior Cesar Avanzi³ , Ricardo Carvalho ${ }^{4}$, Fabiana Silva de Souza \\ José Luiz Andrade Rezende Pereira ${ }^{6}$, Aretusa Daniela Resende Mendes ${ }^{7}$, Gabriel Barreto Macêdo ${ }^{8}$
}

\begin{abstract}
MAIZE NUTRITION AND DRY MATTER YIELD

UNDER LIMING AND SULFUR FERTILIZATION

Liming is essential for obtaining high yield levels in tropical acid soils. The objective of this study was to evaluate maize nutrition and dry matter yield in soil under liming estimated by three calculation methods and sulfur fertilization. The experiment was carried out under greenhouse conditions, in PVC cylinders, by using one plant per cylinder. Filler dolomite lime was added to an Oxisol collected from native forest, at the 4.2 $\mathrm{Mg} \mathrm{ha}^{-1}$, 6.7 $\mathrm{Mg} \mathrm{ha}^{-1}$, and 8.0 $\mathrm{Mg} \mathrm{ha}^{-1}$ doses, respectively calculated by the exchangeable aluminum, magnesium, and calcium method; base saturation method; and SMP buffer method, combined with three sulfur doses $\left(10 \mathrm{mg} \mathrm{dm}^{-3}\right.$, $30 \mathrm{mg} \mathrm{dm}^{-3}$, and $60 \mathrm{mg} \mathrm{dm}^{-3}$ ). Control treatments without lime or sulfur were also included. Maize plants were harvested at 45 days after sowing and divided into shoots and roots. The most efficient lime recommendation method for maize was the base saturation method. The application of sulfur doses did not affect the maize development up to the evaluated stage.
\end{abstract}

KEY-WORDS: Zea mayz; soil acidity; dry mass; root development.

\section{INTRODUÇÃO}

Solos tropicais ácidos são caracterizados, em sua maioria, pela alta concentração de Al trocável, baixo teor de $\mathrm{P}$ disponível e alta capacidade de adsorção de nutrientes (Gaume et al. 2001). As raízes das plantas não se desenvolvem bem nestes solos, princi-

\section{RESUMO}

A calagem é uma prática indispensável para obtenção de altos rendimentos das culturas, em solos tropicais ácidos. Objetivou-se avaliar a nutrição e produção de matéria seca de milho, em solo submetido a calagem estimada por três métodos de cálculo e adubação sulfatada. O experimento foi desenvolvido em casa-de-vegetação, em tubos de PVC, com uma planta por tubo. Utilizou-se Latossolo Vermelho distrófico (LVd), sob vegetação nativa. Foi aplicado calcário dolomítico, tipo filler, nas doses de 4,2 $\mathrm{Mg} \mathrm{ha}^{-1} ; 6,7 \mathrm{Mg} \mathrm{ha}^{-1}$; e 8,0 $\mathrm{Mg} \mathrm{ha}^{-1}$, calculadas pelo método do alumínio trocável, cálcio e magnésio; método da elevação da saturação por bases; e método do tampão SMP, respectivamente, além do tratamento sem aplicação de calcário, combinados com três doses de $\mathrm{S}\left(10 \mathrm{mg} \mathrm{dm}^{-3}, 30 \mathrm{mg} \mathrm{dm}^{-3}\right.$ e $\left.60 \mathrm{mg} \mathrm{dm}^{-3}\right)$, mais o tratamento sem adição de enxofre. As plantas de milho foram colhidas aos 45 dias após a semeadura, sendo separada a parte aérea do sistema radicular. $\mathrm{O}$ método mais eficiente de recomendação de calagem para o milho foi o método da elevação da saturação por bases. A aplicação de doses de enxofre não teve efeito no desenvolvimento do milho, até o estádio avaliado.

PALAVRAS-CHAVE: Zea mayz; acidez do solo; matéria seca; desenvolvimento radicular.

palmente devido à toxidez de $\mathrm{Al}$ (Pavan et al. 1982) e aos baixos teores de Ca (Ritchey et al. 1982). Desta forma, a prática da calagem torna-se imprescindível para obtenção de elevadas produtividades, devido à melhoria das condições do solo, tais como elevação do $\mathrm{pH}$, redução do teor de $\mathrm{Al}$ trocável, elevação dos teores de cálcio e magnésio disponíveis e aumen-

1. Trabalho recebido em jan./2010 e aceito para publicação em maio/2011 ( ${ }^{\circ}$ registro: PAT 8685/ DOI: 10.5216/pat.v41i2.8685).

2. Instituto Agronômico de Campinas, Centro de Solos e Recursos Ambientais, Campinas, SP, Brasil.

E-mail: leonidasmelobr@yahoo.com.br.

3. Embrapa Pesca e Aquicultura, Palmas, TO, Brasil.E-mail: junior.avanzi@embrapa.br.

4. Du Pont do Brasil S/A, Divisão Pioneer Sementes, Planaltina, DF, Brasil.E-mail: ricardo.carvalho1@pioneer.com.

5. Universidade Federal do Espírito Santo, Departamento de Produção Vegetal, Alegre, ES, Brasil. E-mail: fassouza@yahoo.com.br.

6. Instituto Federal de Educação, Ciência e Tecnologia do Sul de Minas Gerais, Inconfidentes, MG, Brasil.

E-mail: joseluiz.pereira@ifs.ifsuldeminas.edu.br.

7. Universidade Federal de Minas Gerais, Instituto de Ciências Agrárias, Montes Claros, MG, Brasil.

E-mail: aretusadaniela@bol.com.br.

8. Instituto Nacional de Colonização e Reforma Agrária, Divisão de Obtenção de Terras, Salvador, BA, Brasil.

E-mail: gabriel.barreto@sdr.incra.gov.br. 
to da disponibilidade de fósforo para as plantas. Forestieri \& De-Polli (1990) observaram incremento médio de 4,8 g/vaso na produção de matéria seca de milho, em Argissolo Vermelho-Amarelo, após a calagem, enquanto Nwachuku \& Loganathan (1991) verificaram aumento significativo dos teores de $\mathrm{Ca} \mathrm{e}$ $\mathrm{Mg}$ nas folhas e colmos de milho.

A quantidade ou dose de corretivo a ser recomendada depende do cálculo da necessidade de calagem utilizado e da resposta das espécies vegetais, em relação à correção da acidez. No Brasil, sobretudo nas regiões Sul e Sudeste, são utilizados três métodos de determinação da necessidade de calagem: o método do tampão SMP (Shoemaker et al. 1961), o baseado nos teores de alumínio trocável e de cálcio e magnésio (CFSEMG 1999) e o método da elevação da saturação por bases (Raij et al. 1997).

A correção da acidez do solo é muito importante ao adequado desenvolvimento do milho, embora existam materiais genéticos mais tolerantes às condições de acidez (Cantarella 1993). O aumento do pH do solo altera a disponibilidade de nutrientes, causando aumentos na absorção de N (Goodroad \& Jellum 1988), P, K e S (Adetunji \& Bamiro 1994) pelo milho.

Nos solos, a maior parte do enxofre se encontra na forma orgânica, podendo representar mais de 90\% do total. Mudanças no manejo do solo, como a introdução da calagem, afetam a taxa de mineralização e a lixiviação do $\mathrm{SO}_{4}^{-2}$ mineralizado (Valeur et al. 2002). Silva et al. (1999) verificaram que a calagem aumenta a intensidade na mineralização do enxofre, em Gleissolo háplico e Latossolo Vermelho-Amarelo. Entretanto, Kliemann \& Malavolta (1993) relataram que a calagem não afeta, de forma significativa, a mineralização do $\mathrm{S}$ em solos arenosos, com baixo teor de carbono.

O aparecimento de sintomas de deficiência de $\mathrm{S}$ vem crescendo nas últimas décadas, devido ao aumento no uso de fertilizantes concentrados livres de enxofre, às colheitas intensivas, à remoção completa dos resíduos da área, à lixiviação e à erosão. Em condições de deficiência de enxofre, a eficiência de aplicação de $\mathrm{N}, \mathrm{P}_{2} \mathrm{O}_{5}$ e $\mathrm{K}_{2} \mathrm{O}$ pode ser seriamente afetada e altas produções podem não ser sustentáveis (Khan et al. 2006). Weil \& Mughogho (2000), estudando a resposta do milho ao enxofre pela caracterização nutricional, em quatro regiões de Malawi, na África, obtiveram resposta média de produção de 90-142 kg grão/kg de S aplicado, empregando doses de $5-10 \mathrm{~kg} \mathrm{ha}^{-1}$ de $\mathrm{S}$.
No Brasil, em áreas de Cerrado, é necessária a aplicação de grandes quantidades de fertilizantes fosfatados, que, nem sempre, são aplicados simultaneamente com fontes de enxofre, devido ao uso de fórmulas concentradas de fertilizantes, tornando mais frequentes os problemas de deficiência de enxofre (Hitsuda et al. 2005) e colocando em risco a obtenção de altos rendimentos. Além disto, em solo que recebe calcário, o enxofre pode ser lixiviado, devido ao aumento de cargas negativas, e geralmente se acumula nas camadas de subsolo.

Há grande variação nas doses de calcário recomendadas pelos métodos de cálculo da necessidade de calagem para uma mesma região, clima, solo e cultivar utilizada e a influência da calagem na dinâmica do enxofre no solo deve ser avaliada visando a evitar possíveis deficiências deste nutriente na cultura do milho. Assim, espera-se que haja diferença entre a quantidade de calcário recomendada pelos métodos mais comuns de recomendação de calagem, afetando a disponibilidade de enxofre, e, consequentemente, a produtividade do milho. Neste contexto, objetivou-se avaliar a nutrição e a produção de matéria seca de milho, em solo submetido a calagem estimada por três métodos de cálculo e adubação sulfatada.

\section{MATERIAL E MÉTODOS}

O experimento foi desenvolvido em casa-de-vegetação, no Departamento de Ciência do Solo da Universidade Federal de Lavras (UFLa), Minas Gerais, em 2006. As amostras foram coletadas em Latossolo Vermelho distrófico típico (LVd), nas profundidades de 0-0,2 m e 0,2-0,4 m, localizado no campus da Universidade, em área sob vegetação nativa.

Realizou-se a caracterização química do solo, na camada de 0-0,2 m, sob condições naturais (Tabela 1). O Ca e Mg foram extraídos com solução de $\mathrm{KCl} 1 \mathrm{~mol} \mathrm{~L}^{-1}$ e determinados em absorção atômica, no modo de chama ar-acetileno. O P e K foram extraídos por solução de Mehlich-1 e determinados por colorimetria e fotometria de chama, respectivamente. Os micronutrientes ( $\mathrm{Zn}, \mathrm{Cu}$ e $\mathrm{Mn}$ ) foram extraídos por DTPA e determinados por absorção atômica. $\mathrm{O} \mathrm{S}-\mathrm{SO}_{4}$ foi extraído com fosfato de cálcio e determinado por turbidimetria, pela reação com $\mathrm{BaCl}_{2}$. O B foi determinado pelo método da água quente e a MO por titulação com sulfato ferroso amoniacal, após oxidação úmida com dicromato de potássio. Nestas condições, o solo apresentava baixos 
Tabela 1. Caracterização química do solo em condições naturais, na camada 0-0,2 m (Lavras, MG, 2006).

\begin{tabular}{|c|c|c|c|c|c|c|c|c|c|c|c|c|}
\hline \multirow{2}{*}{$\mathrm{pH}\left(\mathrm{H}_{2} \mathrm{O}\right)$} & $\mathrm{P}$ & $\mathrm{K}$ & $\mathrm{Ca}$ & $\mathrm{Mg}$ & $\mathrm{V}$ & $\mathrm{m}$ & $\mathrm{MO}$ & $\mathrm{Zn}$ & $\mathrm{Mn}$ & $\mathrm{Cu}$ & $\mathrm{B}$ & $\mathrm{S}_{-} \mathrm{SO}_{4}$ \\
\hline & \multicolumn{2}{|c|}{$-\mathrm{mg} \mathrm{dm}^{-3}-$} & \multicolumn{2}{|c|}{$-\mathrm{cmol}_{\mathrm{c}} \mathrm{dm}^{-3}$} & \multicolumn{3}{|c|}{$\%$} & \multicolumn{5}{|c|}{$-m g d m^{-3}$} \\
\hline 5,2 & 1,0 & 34 & 0,3 & 0,1 & 11 & 47 & 4,5 & 3,2 & 0,5 & 1,2 & 1,4 & 23 \\
\hline
\end{tabular}

teores de nutrientes e acidez elevada. A partir destes resultados analíticos, foram calculadas as doses de calcário para correção da acidez, de acordo com as recomendações técnicas para a cultura do milho. A necessidade de calagem foi calculada pelos três métodos comumente utilizados: método do tampão SMP, método de elevação da saturação por bases e método dos teores de alumínio trocável e de cálcio e magnésio. As doses calculadas foram: $8,0 \mathrm{Mg} \mathrm{ha}^{-1}$; 6,7 $\mathrm{Mg} \mathrm{ha}^{-1}$; e 4,2 $\mathrm{Mg} \mathrm{ha}^{-1}$, respectivamente, para os referidos métodos. No solo da camada $0-0,2 \mathrm{~m}$, aplicaram-se as doses de calcário dolomítico do tipo filler $(\mathrm{PRNT}=102 \%)$. A mistura solo + calcário foi homogeneizada em um recipiente plástico, sendo a umidade mantida próxima a $80 \%$ da capacidade máxima de retenção de água, mediante pesagens dos vasos. Realizou-se incubação, por um período de 30 dias.

O delineamento experimental adotado foi o inteiramente casualizado, com três repetições (4x4x3). Os tratamentos consistiram da combinação de três doses de calcário $\left(4,2 \mathrm{Mg} \mathrm{ha}^{-1} ; 6,7 \mathrm{Mg} \mathrm{ha}^{-1}\right.$; e $8,0 \mathrm{Mg} \mathrm{ha}^{-1}$ ), além do tratamento sem aplicação de calcário, combinados com três doses de enxofre (10 $\mathrm{mg} \mathrm{kg}^{-1}, 30 \mathrm{mg} \mathrm{kg}^{-1}$ e $60 \mathrm{mg} \mathrm{kg}^{-1}$ ), mais um tratamento sem adição de enxofre. Além disto, aplicaram-se, na adubação básica de plantio, $300 \mathrm{mg} \mathrm{kg}^{-1} \mathrm{de} \mathrm{P}$; $0,5 \mathrm{mg} \mathrm{kg}^{-1}$ de B; $1,5 \mathrm{mg} \mathrm{kg}^{-1}$ de Cu; $4 \mathrm{mg} \mathrm{kg}^{-1}$ de Mn; e $2 \mathrm{mg} \mathrm{kg}^{-1}$ de $\mathrm{Zn}$. A aplicação de $\mathrm{S}$ e adubação de plantio foram realizadas um dia antes da semeadura. Utilizaram-se tubos de PVC com $10 \mathrm{~cm}$ de diâmetro, em duas camadas: 0-0,2 $\mathrm{m}$ (solo que recebeu os tratamentos) e 0,2-0,4 m (solo natural - sem tratamento).

Foi realizada semeadura de 3 sementes do híbrido simples UFLA 2004 por tubo. Cinco dias após a emergência, realizou-se desbaste, deixando-se apenas uma planta por tubo. Durante a condução do experimento, a umidade foi mantida próxima a $80 \%$ da capacidade máxima de retenção de água, por meio de pesagens diárias dos tubos. A adubação de cobertura foi realizada aos 20,25 e 30 dias após a semeadura, parcelando-se a aplicação de $300 \mathrm{mg} \mathrm{kg}^{-1}$ de $\mathrm{N}$ e $300 \mathrm{mg} \mathrm{kg}^{-1}$ de $\mathrm{K}$. O experimento foi condu- zido até os 45 dias após a semeadura. A parte aérea e o sistema radicular foram separados, sendo que as raízes foram lavadas, para a retirada de todo o solo aderido. Todo o material vegetal foi seco em estufa com circulação forçada de ar, a $60^{\circ} \mathrm{C}$, até massa constante, para avaliação do rendimento da matéria seca. Posteriormente, as amostras foram moídas em moinho tipo Willey e realizou-se a digestão com ácido sulfúrico, para determinação dos teores de $\mathrm{N}$ (método keijdhal), e digestão nitríco-perclórica, para determinação de $\mathrm{P}, \mathrm{K}, \mathrm{Ca}, \mathrm{Mg}, \mathrm{S}, \mathrm{Cu}, \mathrm{Fe}, \mathrm{Mn}$ e $\mathrm{Zn}$. A partir destes resultados, calculou-se o acúmulo destes nutrientes na parte aérea das plantas de milho.

Os dados foram submetidos a análise de variância, aplicando-se o teste F para verificar a significância $(\mathrm{p}<0,05)$ do efeito de cada tratamento. Para as variáveis em que o teste $\mathrm{F}$ mostrou-se significativo, foram realizadas análises de regressão.

\section{RESULTADOS E DISCUSSÃO}

As doses de calcário não apresentaram interação significativa com as doses de enxofre. Em função disto, estas foram discutidas separadamente. Após o cultivo, os teores de S, na camada $0-0,2 \mathrm{~m}$, permaneceram próximos ao teor original do solo antes do cultivo (Tabela 2), mesmo onde foram aplicadas doses deste elemento. Para as doses de enxofre aplicadas, houve efeito significativo no acúmulo de enxofre e ferro. $\mathrm{O}$ acúmulo de $\mathrm{S}$ aumentou linearmente com as doses aplicadas (Figura 1). Entretanto, para os demais nutrientes avaliados, não houve interação significativa.

Após o cultivo do milho, os teores de $\mathrm{P}$ e, principalmente, de $\mathrm{K}$ reduziram-se sensivelmente, em relação ao tratamento controle (Tabela 2). Isto ocorreu devido ao acúmulo destes elementos pelo milho (parte aérea e raízes), proporcionado pelo maior desenvolvimento das plantas, propiciado pela calagem.

Nas doses mais elevadas de calcário $\left(6,7 \mathrm{Mg} \mathrm{ha}^{-1}\right.$ e $8,0 \mathrm{Mg} \mathrm{ha}^{-1}$ ), esperava-se que houvesse efeito residual do mesmo, visto que, após o cultivo, os teores de $\mathrm{Ca}$ e $\mathrm{Mg}$ permaneceram elevados e todo o $\mathrm{Al}^{3+}$ 
Tabela 2. Caracterização química do solo após o cultivo do milho, na camada 0-0,2 m (Lavras, MG, 2006).

\begin{tabular}{|c|c|c|c|c|c|c|c|c|c|c|c|c|}
\hline \multirow{2}{*}{ Tratamentos } & \multirow{2}{*}{$\mathrm{pH}\left(\mathrm{H}_{2} \mathrm{O}\right)$} & $\mathrm{P}$ & K & $\mathrm{Ca}$ & $\mathrm{Mg}$ & $\mathrm{V}$ & $\mathrm{m}$ & $\mathrm{Zn}$ & $\mathrm{Mn}$ & $\mathrm{Cu}$ & $\mathrm{B}$ & $\mathrm{S}_{-} \mathrm{SO}_{4}$ \\
\hline & & \multicolumn{2}{|c|}{$-\mathrm{mg} \mathrm{dm}^{-3}-$} & \multicolumn{2}{|c|}{$-\mathrm{cmol}_{\mathrm{c}} \mathrm{dm}^{-3}-$} & \multicolumn{2}{|c|}{ - $\%$} & \multicolumn{5}{|c|}{$\mathrm{mg} \mathrm{dm}^{-3}$} \\
\hline $0 * / 0 * *$ & 4,8 & 19,4 & 168 & 0,5 & 0,2 & 11 & 47 & 2,8 & 6,0 & 1,9 & 0,4 & 24 \\
\hline $0 / 10$ & 4,9 & 25,6 & 168 & 0,3 & 0,1 & 8 & 55 & 2,1 & 5,4 & 1,6 & 0,4 & 25 \\
\hline $0 / 30$ & 4,7 & 25,6 & 168 & 0,4 & 0,1 & 9 & 52 & 2,3 & 5,7 & 1,5 & 0,3 & 29 \\
\hline $0 / 60$ & 4,7 & 22,9 & 168 & 0,3 & 0,1 & 9 & 57 & 2,1 & 5,6 & 1,3 & 0,4 & 34 \\
\hline $4,2 / 0$ & 5,4 & 12,4 & 22 & 2,8 & 1,0 & 41 & 5 & 3,0 & 11,3 & 1,4 & 0,5 & 20 \\
\hline $4,2 / 10$ & 5,5 & 19,4 & 20 & 2,6 & 1,4 & 39 & 5 & 2,3 & 9,5 & 1,4 & 0,3 & 22 \\
\hline $4,2 / 30$ & 5,4 & 21,1 & 28 & 2,8 & 1,0 & 38 & 5 & 2,4 & 6,8 & 1,6 & 0,3 & 29 \\
\hline $4,2 / 60$ & 5,4 & 16,9 & 19 & 2,8 & 0,6 & 38 & 8 & 2,3 & 9,5 & 1,4 & 0,4 & 34 \\
\hline $6,7 / 0$ & 5,6 & 14,1 & 25 & 4,2 & 1,2 & 55 & 0 & 2,8 & 10,6 & 1,3 & 0,2 & 23 \\
\hline $6,7 / 10$ & 5,7 & 14,1 & 16 & 4,3 & 1,6 & 60 & 0 & 2,8 & 11,2 & 1,4 & 0,4 & 24 \\
\hline $6,7 / 30$ & 5,8 & 15,0 & 19 & 3,8 & 1,6 & 55 & 0 & 2,6 & 8,5 & 1,4 & 0,4 & 29 \\
\hline $6,7 / 60$ & 5,7 & 14,1 & 19 & 4,0 & 1,2 & 54 & 0 & 2,7 & 10,7 & 1,3 & 0,4 & 40 \\
\hline $8 / 0$ & 5,7 & 13,2 & 17 & 4,0 & 1,4 & 58 & 0 & 2,8 & 10,6 & 1,1 & 0,4 & 23 \\
\hline $8 / 10$ & 5,8 & 14,5 & 22 & 4,1 & 1,8 & 60 & 0 & 2,8 & 11,0 & 1,0 & 0,5 & 26 \\
\hline $8 / 30$ & 6,0 & 15,0 & 11 & 3,8 & 2,0 & 59 & 0 & 2,6 & 10,4 & 1,1 & 0,4 & 28 \\
\hline $8 / 60$ & 5,7 & 15,0 & 17 & 4,1 & 1,7 & 62 & 0 & 2,8 & 11,2 & 1,2 & 0,5 & 26 \\
\hline
\end{tabular}

* Dose de calcário em $\mathrm{Mg} \mathrm{ha}^{-1}$. ** Dose de enxofre em $\mathrm{mg} \mathrm{dm}^{-3}$.

encontrava-se precipitado. Andreotti et al. (2001), após elevar a saturação por bases do solo a $70 \%$, verificaram este efeito residual por três cultivos sucessivos de milho, em condições de casa-de-vegetação.

Para todos os macronutrientes, foi observada resposta quadrática no acúmulo na parte aérea, em função das doses de calcário (Figura 2). Os acúmulos máximos para $\mathrm{N}, \mathrm{P}, \mathrm{K}, \mathrm{Ca}, \mathrm{Mg}$ e $\mathrm{S}$ foram observados, respectivamente, nas doses de $6,1 \mathrm{Mg} \mathrm{ha}^{-1}$; 7,5 $\mathrm{Mg} \mathrm{ha}^{-1} ; 6,5 \mathrm{Mg} \mathrm{ha}^{-1} ; 6,6 \mathrm{Mg} \mathrm{ha}^{-1} ; 6,9 \mathrm{Mg} \mathrm{ha}^{-1} ; \mathrm{e}$ $6,8 \mathrm{Mg} \mathrm{ha}^{-1}$. Estes resultados podem ser explicados em função da maior disponibilidade dos nutrientes

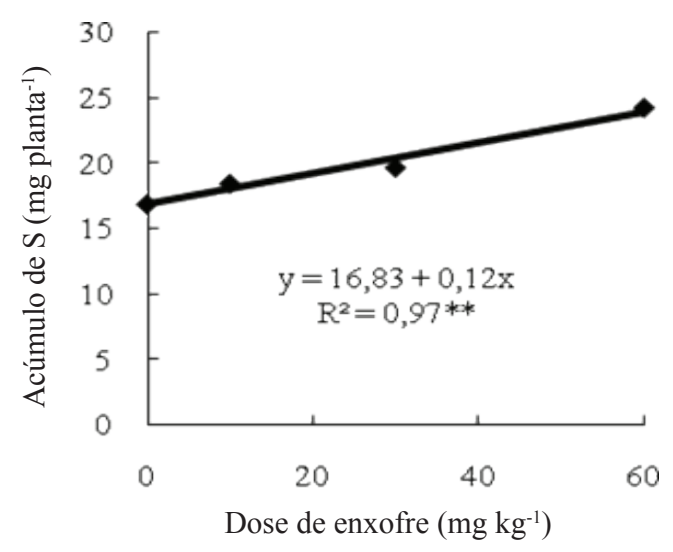

Figura 1. Acúmulo de enxofre na parte aérea, em função das doses de enxofre (Lavras, MG, 2006). e redução do alumínio tóxico, devido ao efeito da calagem no solo, elevando o $\mathrm{pH}$ para valores próximos a 6,0, que é o valor ideal para a cultura do milho (CFSEMG 1999). Entre todos os macronutrientes, o P foi aquele que mostrou maior acúmulo na dose mais elevada de calcário $\left(7,5 \mathrm{Mg} \mathrm{ha}^{-1}\right)$, provavelmente devido à maior disponibilidade deste nutriente, proporcionada pela calagem. O decréscimo no acúmulo dos macronutrientes, nas doses mais elevadas de calcário aplicadas ao solo, pode ter sido ocasionado pelo menor crescimento das plantas, sob estas doses (Figura 2).

$\mathrm{Na}$ ausência de calagem, foram observados menores acúmulos de macronutrientes (Figura 2), devido ao menor desenvolvimento do sistema radicular, à acidez elevada do solo, ao alto teor de alumínio tóxico, ao baixo valor da CTC (Tabela 1) e à menor mineralização da matéria orgânica do solo.

Para os micronutrientes (Figura 3), as curvas de acúmulo de $\mathrm{Mn}, \mathrm{Zn}$ e Fe, na parte aérea, em função das doses de calcário, também seguiram o modelo quadrático, com os acúmulos máximos ocorrendo, respectivamente, nas doses de $5,5 \mathrm{Mg} \mathrm{ha}^{-1}$; 5,3 $\mathrm{Mg} \mathrm{ha}^{-1}$; e 5,0 $\mathrm{Mg} \mathrm{ha}^{-1}$. Estes resultados podem ser explicados pela menor disponibilidade de micronutrientes no solo, em valores de $\mathrm{pH}$ mais elevados. Consequentemente, a absorção pode ser reduzida e, além disto, nas maiores doses, verificou-se menor 


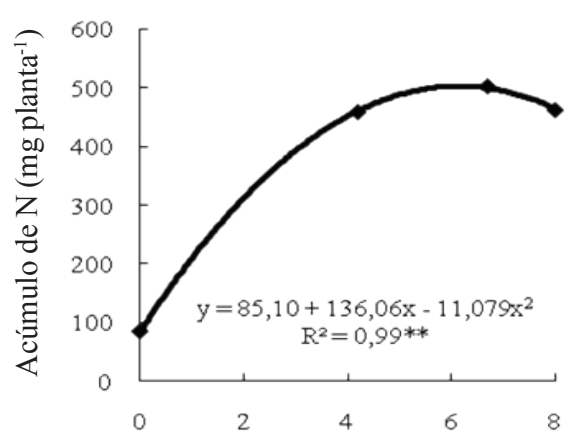

a
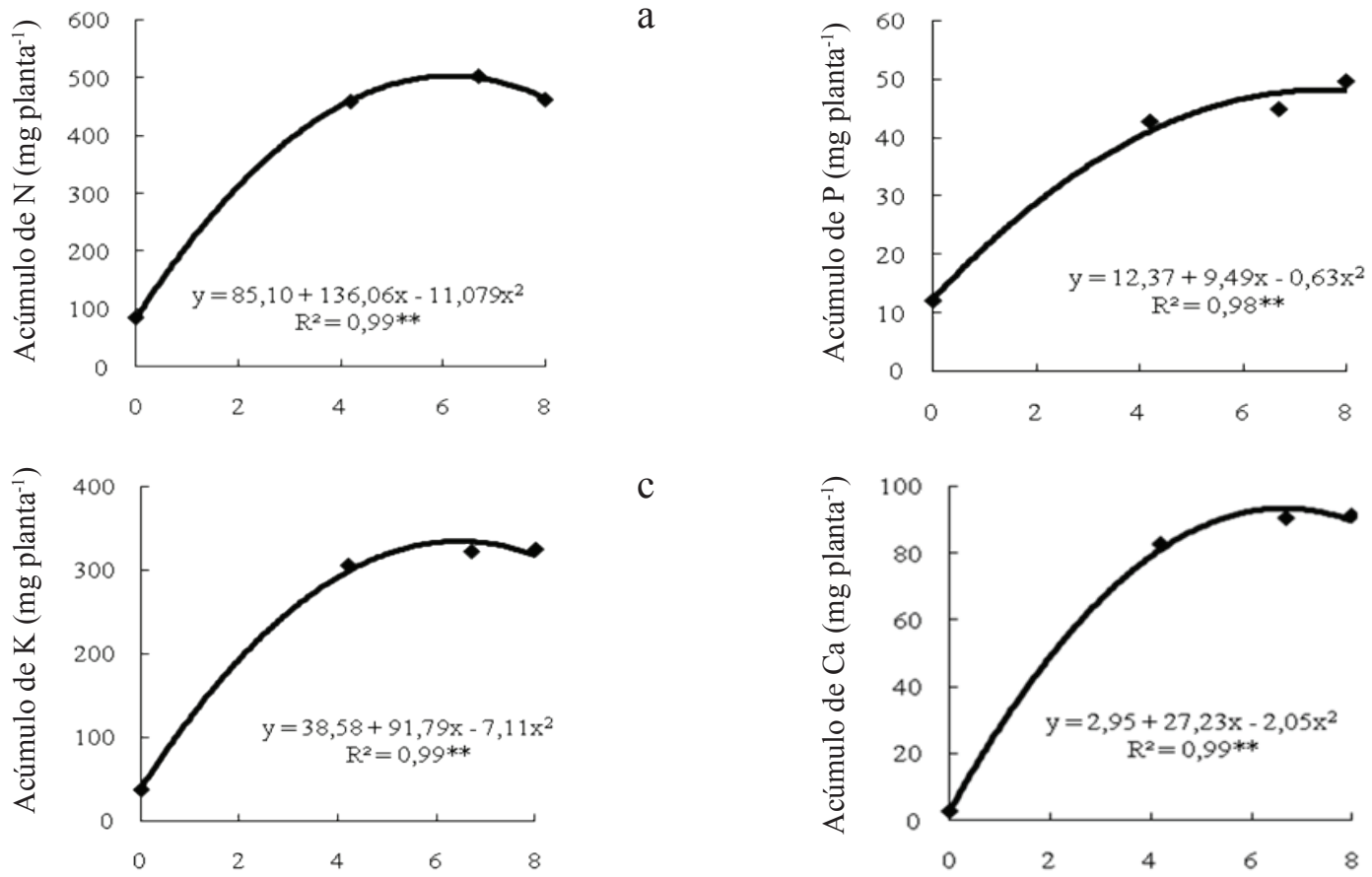

c
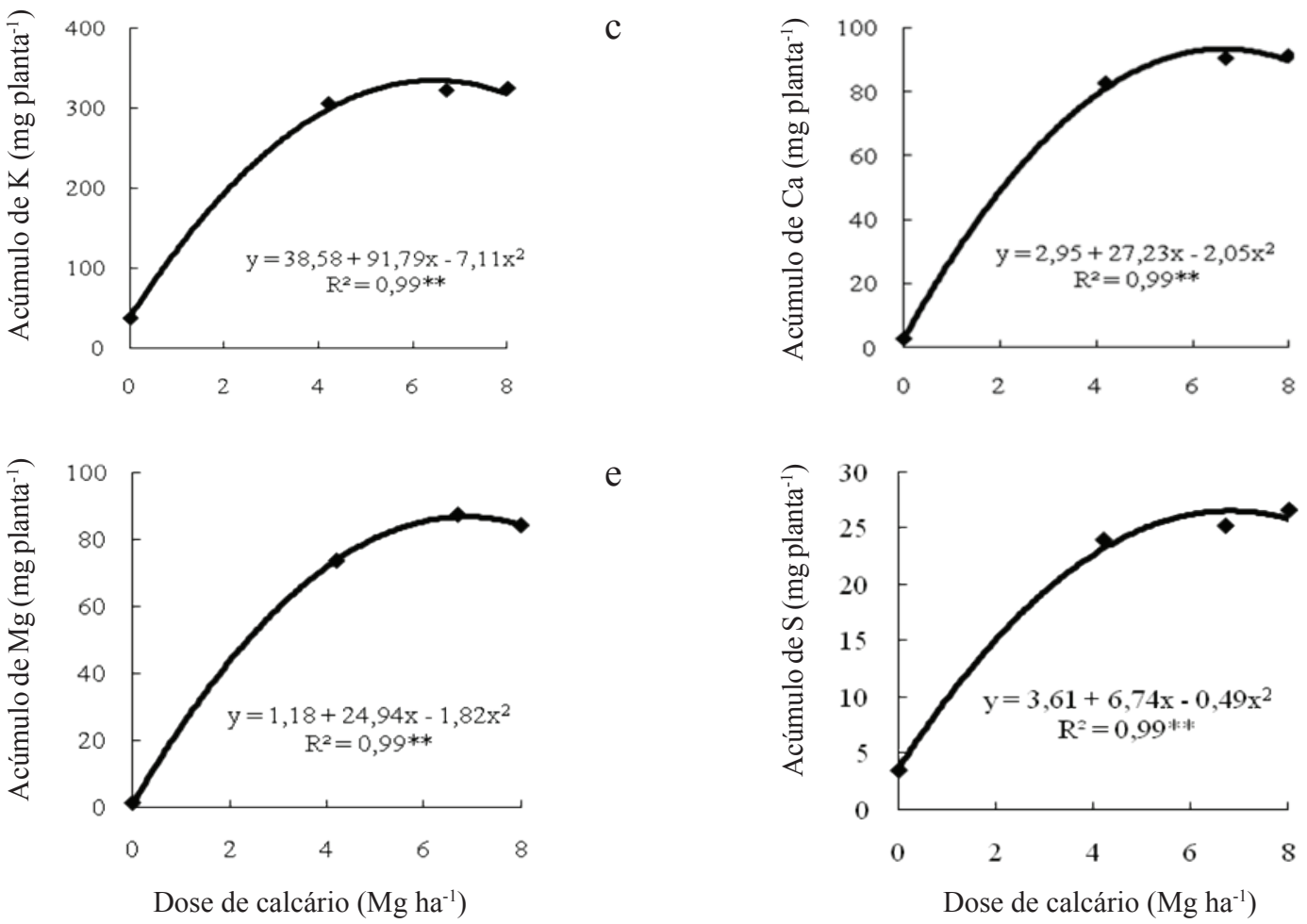

Figura 2. Acúmulo dos macronutrientes nitrogênio (a), fósforo (b), potássio (c), cálcio (d), magnésio (e) e enxofre (f) na parte aérea, em função de doses de calcário calculadas por diferentes métodos de recomendação de calagem (Lavras, MG, 2006).

crescimento das plantas (Figura 4). No tratamento sem aplicação de calcário, esperava-se maior disponibilidade de micronutrientes para a solução do solo. Entretanto, os acúmulos destes elementos foram baixos, devido ao pequeno desenvolvimento do sistema radicular, comprometendo sua absorção (Tabela 2). Para $\mathrm{Cu}$, foi observado efeito linear, sendo o acúmulo diretamente proporcional ao acréscimo nas doses de calcário. Este efeito pode ter ocorrido em razão do maior desenvolvimento das raízes, uma vez que o $\mathrm{Cu}$ é relativamente imóvel no solo e, na sua maior parte, é absorvido por interceptação radicular.

De acordo com estes resultados, o método que mais se aproximou das doses de calcário que propor- cionaram o maior acúmulo de macronutrientes foi o método da saturação por bases, cuja recomendação foi de $6,7 \mathrm{Mg} \mathrm{ha}^{-1}$. Para os micronutrientes, a dose recomendada por este método provocou uma pequena diminuição no acúmulo, não comprometendo, no entanto, o nível nutricional da planta.

Não houve diferença estatística na produção de matéria seca da parte aérea e das raízes, nas duas camadas, em função da aplicação de doses de enxofre (dados não apresentados). Isto pode ser explicado devido ao alto valor inicial de $\mathrm{S}$ e, também, ao teor de matéria orgânica no solo, que contribuíram para o suprimento deste elemento, durante o cultivo do milho. 


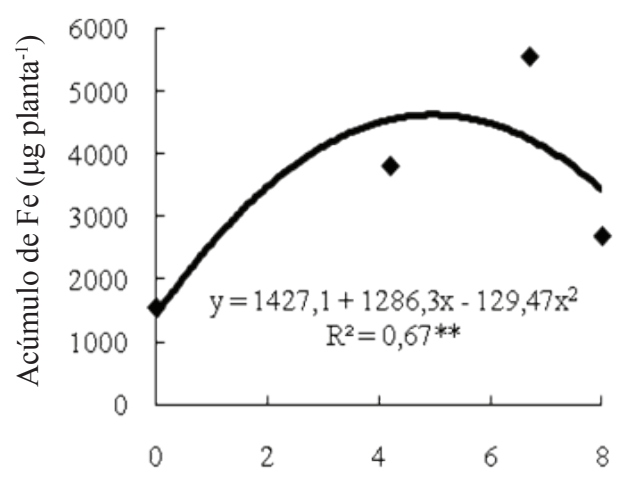

a

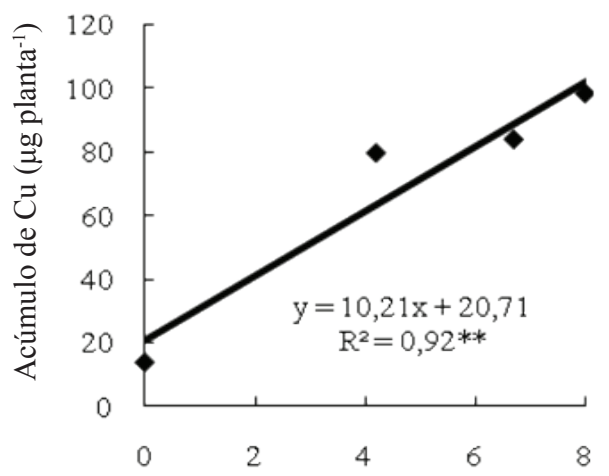

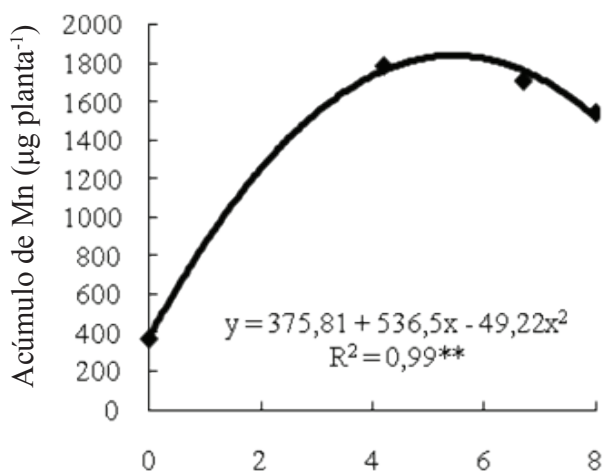

Dose de calcário $\left(\mathrm{Mg} \mathrm{ha}^{-1}\right)$

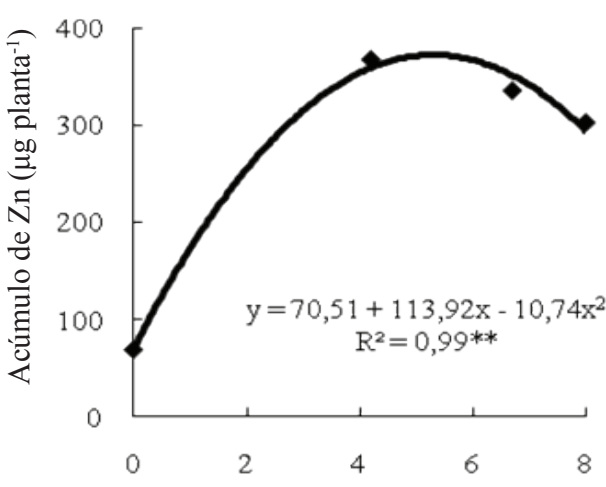

Dose de calcário $\left(\mathrm{Mg} \mathrm{ha}^{-1}\right)$

Figura 3. Acúmulo dos micronutrientes ferro (a), cobre (b), manganês (c) e zinco (d) na parte aérea, em função de doses de calcário calculadas por diferentes métodos de recomendação de calagem (Lavras, MG, 2006).
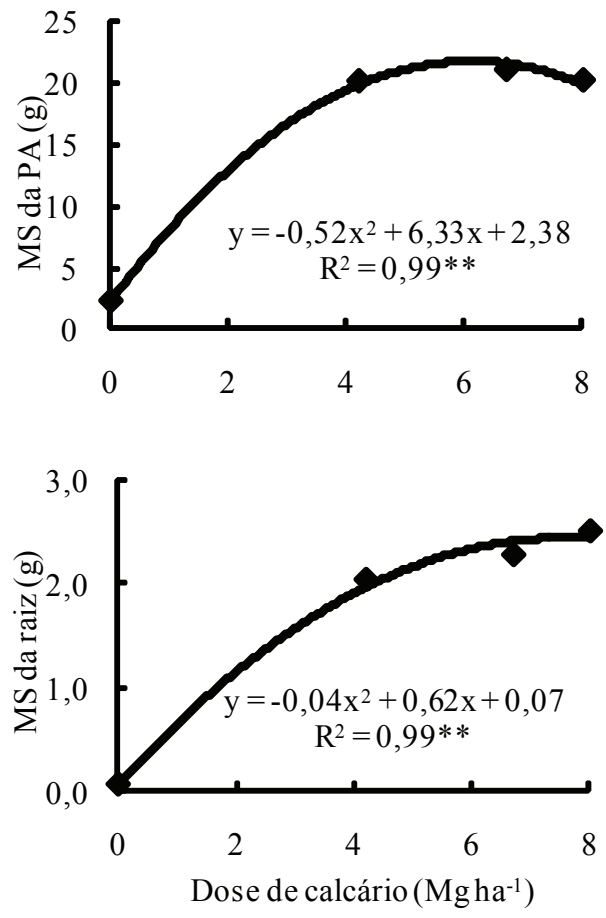

a

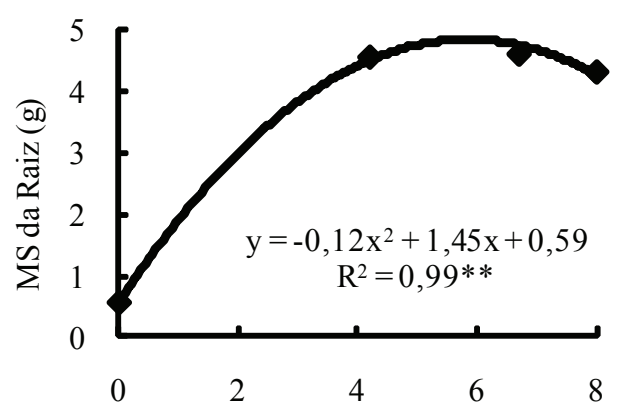

C

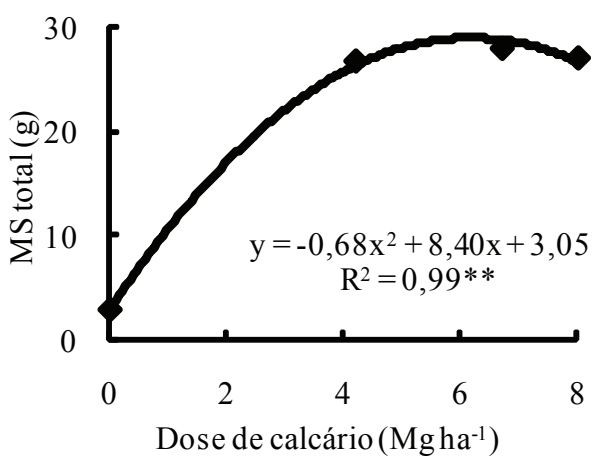

Figura 4. Matéria seca da parte aérea (a) e das raízes, nas camadas 0-20 cm (b) e 20-40 cm (c), e matéria seca total (d), em função de doses de calcário calculadas por diferentes métodos de recomendação de calagem (Lavras, MG, 2006). 
Na produção da matéria seca da parte aérea e das raízes, nas camadas $0-0,2 \mathrm{~m}$ e 0,2-0,4 m, e matéria seca total, houve efeito quadrático, em função das doses de calcário aplicadas, sendo os maiores valores observados, respectivamente, nas doses de 6,1 $\mathrm{Mg} \mathrm{ha}^{-1} ; 5,8 \mathrm{Mg} \mathrm{ha}^{-1} ; 7,6 \mathrm{Mg} \mathrm{ha}^{-1}$; e 6,2 $\mathrm{Mg} \mathrm{ha}^{-1}$ (Figura 4). O método de recomendação de calagem que melhor aproximou-se da dose, para atingir a máxima produção de matéria seca da parte aérea (MSPA); matéria seca de raiz (MSR), na camada 0-0,2 m; e matéria seca total, foi o método da saturação por bases. Já para a MSR, na camada 0,2-0,4 m, o método SMP esteve mais próximo, provavelmente devido à maior movimentação de Ca para esta camada, proporcionando um ambiente mais adequado para o desenvolvimento radicular.

\section{CONCLUSÕES}

1. O método mais eficiente de recomendação de calagem para a cultura do milho foi o método de saturação por bases, o qual proporcionou maior acúmulo de macronutrientes e maior produção de matéria seca.

2. Para os micronutrientes, o método baseado nos teores de alumínio trocável e de cálcio e magnésio foi o que apresentou o maior acúmulo para estes elementos.

3. A aplicação de doses de enxofre não teve efeito na produção de matéria seca do milho, até o estádio avaliado.

\section{REFERÊNCIAS}

ADETUNJI, M. T.; BAMIRO, F. O. Effect of lime on soil properties, $\mathrm{N}$ nutrition and nutrient uptake of maize in some Nigerian soils. African Crop Science Journal, Kampala, v. 2, n. 2, p. 183-187, 1994.

ANDREOTTI, M.; SOUZA, E. C. A.; CRUSCIOL, C. A. C. Componentes morfológicos e produção de matéria seca de milho em função da aplicação de calcário e zinco. Scientia Agricola, Piracicaba, v. 58, n. 2, p. 321-327, 2001.

CANTARELLA, H. Calagem e adubação do milho. In: BÜLL, L. T.; CANTARELLA, H. (Eds). Cultura do milho: fatores que afetam a produtividade. Piracicaba: Potafos, 1993. p. 147-196.

COMISSÃO DE FERTILIDADE DO SOLO DO ESTADO DE MINAS GERAIS (CFSEMG). Recomendações para $o$ uso de corretivos e fertilizantes em Minas Gerais. $5^{\mathrm{a}}$ aproximação. Viçosa: DFSEMG, 1999.
FORESTIERI, E. F.; DE-POLLI, H. Calagem, enxofre e micronutrientes no crescimento do milho e da mucuna preta num Podzólico Vermelho-Amarelo. Revista Brasileira de Ciência do Solo, Viçosa, v. 14, n. 2, p. 167-172, 1990.

GAUME, A.; MÄCHLER, F.; FROSSARD, E. Aluminum resistance in two cultivars of Zea mays L.: root exudation of organic acids and influence of phosphorus nutrition. Plant and Soil, Amsterdam, v. 234, n. 1, p. 73-81, 2001.

GOODROAD, L. L.; JELLUM, M. D. Effect of N fertilizer rate and soil $\mathrm{pH}$ on $\mathrm{N}$ efficiency in corn. Plant and Soil, Amsterdam, v. 106, n. 1, p. 85-89, 1988.

HITSUDA, K.; YAMADA, M.; KLEPKER, D. Sulfur requirement of eight crops at early stages of growth. Agronomy Journal, Madison, v. 97, n. 1, p. 155-159, 2005.

KHAN, M. J. et al. Response of maize to different levels of sulfur. Communications in Soil Science and Plant Analysis, London, v. 37, n. 1, p. 41-51, 2006.

KLIEMANN, H. J.; MALAVOLTA, E. Disponibilidade de enxofre em solos brasileiros: I. Avaliação dos potenciais de mineralização de nitrogênio e enxofre por incubação aberta. Pesquisa Agropecuária Tropical, Goiânia, v. 23, n. 1, p. 129-144, 1993.

NWACHUKU, D. A.; LOGANATHAN, P. The effect of liming on maize yield and soil properties in Southern Nigeria. Communications in Soil Science and Plant Analysis, London, v. 22, n. 7, p. 623-639, 1991.

PAVAN, M. A.; BINGHAM, F. T.; PRATT, P. F. Toxicity of aluminum to coffee in Ultisols and Oxisols amended with $\mathrm{CaCO}_{3}$ and $\mathrm{CaSO}_{4} \cdot 2 \mathrm{H}_{2} \mathrm{O}$. Soil Science Society of America Journal, Madison, v. 46, n. 5, p. 1201-1207, 1982.

RAIJ, B. V. et al. (Eds.). Recomendações de adubação e calagem para o Estado de São Paulo. 2. ed. rev. atual. Campinas: Instituto Agronômico/Fundação IAC, 1997. (Boletim técnico, 100).

RITCHEY, K. D.; SILVA, J. E.; COSTA, U. F. Calcium deficiency in clayey B horizons of savannah Oxisols. Soil Science, Baltimore, v. 133, n. 6, p. 378-382, 1982.

SHOEMAKER, H. E.; McLEAN, E. O.; PRATT, P. F. Buffer methods for determining the lime requirement of soils with appreciable amounts of extractable aluminum. Soil Science Society of America Journal, Madison, v. 25, n. 4, p. 274-277, 1961.

SILVA, C. A. et al. Mineralização de nitrogênio e enxofre em solos brasileiros sob influência da calagem e fósforo. Pesquisa Agropecuária Brasileira, Brasília, DF, v. 34, n. 9, p. 1679-1689, 1999.

VALEUR, I. et al. Net sulfur mineralization in forest soil as influenced by different lime application rates. Soil Biology and Biochemistry, Amsterdam, v. 34 n. 9, p. 1291-1298, 2002.

WEIL, R. R.; MUGHOGHO, S. K. Sulfur nutrition of maize in four regions of Malawi. Agronomy Journal, Madison, v. 92, n. 4, p. 649-656, 2000. 